Flavour

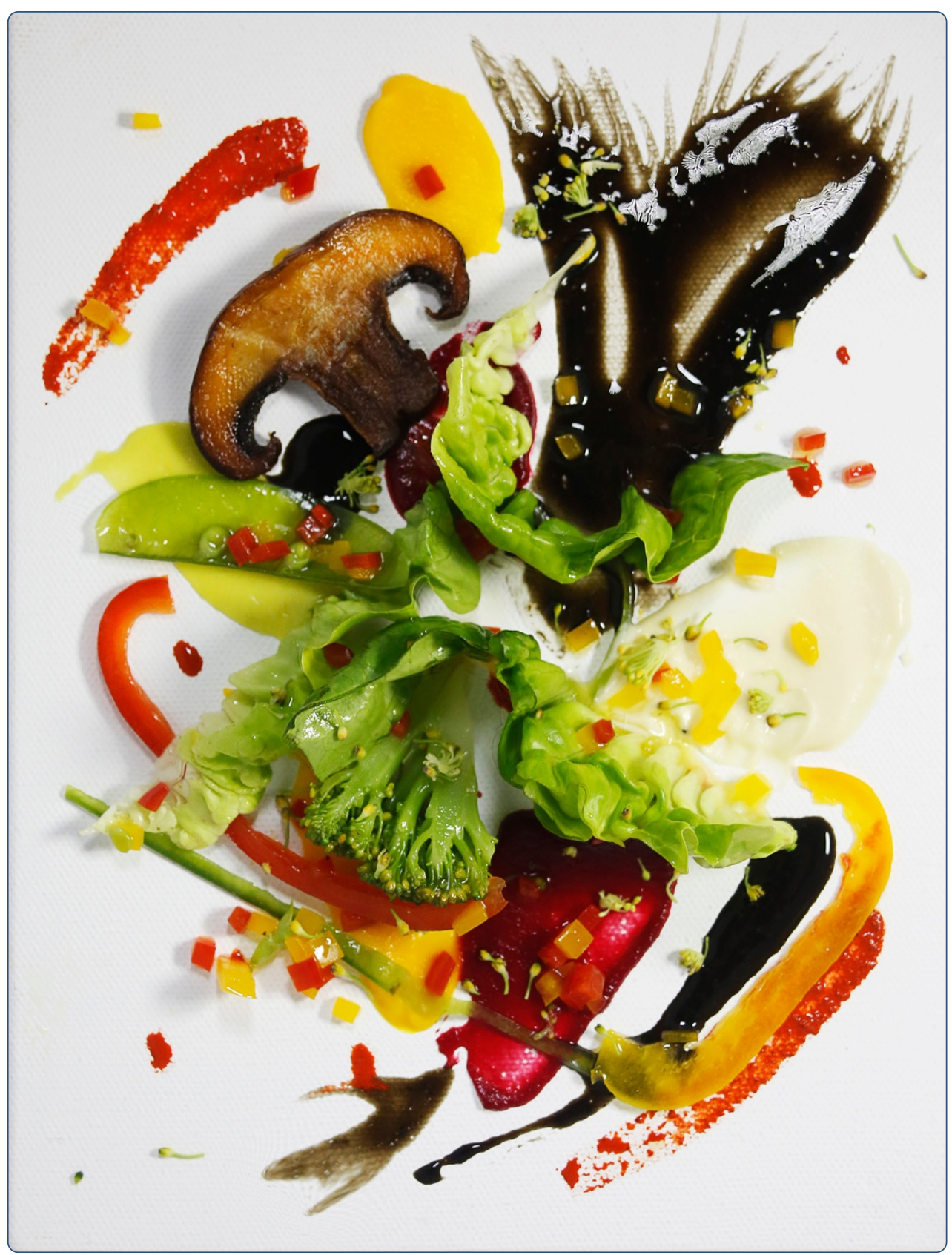

A taste of Kandinsky: assessing the influence of the artistic visual presentation of food on the dining experience

Michel et al. 


\title{
A taste of Kandinsky: assessing the influence of the artistic visual presentation of food on the dining experience
}

\author{
Charles Michel, , Carlos Velasco, Elia Gatti and Charles Spence
}

\begin{abstract}
Background: Researchers have demonstrated that a variety of visual factors, such as the colour and balance of the elements on a plate, can influence a diner's perception of, and response to, food. Here, we report on a study designed to assess whether placing the culinary elements of a dish in an art-inspired manner would modify the diner's expectations and hence their experience of food. The dish, a salad, was arranged in one of three different presentations: One simply plated (with all of the elements of the salad tossed together), another with the elements arranged to look like one of Kandinsky's paintings, and a third arrangement in which the elements were organized in a neat (but non-artistic) manner. The participants answered two questionnaires, one presented prior to and the other after eating the dish, to evaluate their expectations and actual sensory experience.

Results: Prior to consumption, the art-inspired presentation resulted in the food being considered as more artistic, more complex, and more liked than either of the other presentations. The participants were also willing to pay more for the Kandinsky-inspired plating. Interestingly, after consumption, the results revealed higher tastiness ratings for the art-inspired presentation.
\end{abstract}

Conclusions: These results support the idea that presenting food in an aesthetically pleasing manner can enhance the experience of a dish. In particular, the use of artistic (visual) influences can enhance a diner's rating of the flavour of a dish. These results are consistent with previous findings, suggesting that visual display of a food can influence both a person's expectations and their subsequent experience of a dish, and with the common assumption that we eat with our eyes first.

Keywords: Food, Art, Perception, Multisensory, Experience, Plating

\section{Background}

'I try to interpret the artist's message and to make it mine, to translate it in my life and in the dishes.' ([1], Massimo Bottura, Chef at Osteria Francescana).

People perceive and appreciate food in a manner that is multisensory [2-4]; that is, information from the different senses is integrated at both the perceptual and semantic levels in order to give rise to specific multisensory experiences. Just imagine, for instance, a typical meal and the

\footnotetext{
* Correspondence: charles.michel@psy.ox.ac.uk

Crossmodal Research Laboratory, Department of Experimental Psychology,

University of Oxford, South Parks Road, OX1 3UD, Oxford, UK
}

variety of factors that play a role in modulating the diner's overall experience [5-7]. These include, amongst other things, the presence of other people [8], the atmosphere or the environment in which the food is consumed $[9,10]$, the cutlery with which we happen to be eating [11,12], and the plateware from which we are eating [13-15].

What people see also exerts a substantial influence over their perception of food and drink [16]. Visual cues such as colour [17] and texture [18] have been shown to exert a significant influence on the perceived flavour and acceptance of foods [19], and techniques typically belonging to the realm of painting and visual communication design have been theorized to be useful and resourceful tools when it comes to designing food experiences [20]. A food's visual features not only affect the perception of the food 
itself but also play a crucial role in driving our foodrelated expectations [21] and guiding our food choices [5].

Delwiche [22] recently reiterated an oft-made claim that people eat first with their eyes (see Apicius [23] for one of the earliest documented claims of this type). Although the complex visual arrangements of the various elements in a dish play an irrefutably important role in determining a diner's overall perception, there are still not many insights from the scientific literature on this matter available to $\mathrm{cu}-$ linary practitioners that would help them enhance the experience of their guests. In one of the few studies to have been published in this area, Debra Zellner and her colleagues assessed the influence of the balance and complexity of the elements in a dish on the perceived attractiveness, willingness to try, and liking [24]. Their results revealed that manipulating the interaction between complexity (increased by the addition of colour) and balance exerted a significant effect on the perceived attractiveness of the presentation and their participants' willingness to try the food. That said, they did not find any effect of these variables on their participants' liking for the food's flavour.

In a follow-up study, Zellner and her colleagues went on to demonstrate that people prefer food when it is presented in a neat, as compared to a messy, arrangement [25]. The neat visual presentation also exerted a positive influence on their participants' willingness to pay and their judgments of perceived quality. While the results of this previous research represent an interesting contribution to the study of how the visual arrangement of food can influence people's perception, there is still a need for researchers to further assess the influence that aesthetic dishes (the plating typically found in fine dining restaurants ${ }^{\mathrm{a}}$ ) exert on dinners. When taken together with Zellner et al.'s studies, the present study helps to highlight different aspects of how the visual presentation of a dish can change the way the diner/consumer will perceive the food.

Specifically, in the present study, we assessed any influence of an abstract-art based dish design on people's food expectations and on their subsequent experience. We compared people's experience of a dish presented in a simple manner, with a dish whose presentation had been inspired by one of Kandinsky's paintings, and a dish in which the elements were arranged neatly, but without any artistic pretensions.

\section{Methods}

\section{Participants}

Sixty participants (mean age of 27.7 years, $\mathrm{SD}=7.2$; ranging from 18 to 58 years), 30 males and 30 females took part in the study. Upon arrival at the laboratory, the participants had to fill in a consent form and a questionnaire in order to assess the existence of any sensory dysfunctions, allergies, or food intolerances. A small number of the participants reported being allergic to, or disliking, certain ingredients, none of which were used in the present study. The experiment was approved by the Ethics Committee of the Department of Experimental Psychology at the University of Oxford. The participants were compensated with five British pounds for their time.

\section{Apparatus and materials}

The stimuli consisted of the same set of ingredients presented in one of three different visual arrangements. Importantly, the visual arrangements characterizing the three conditions contained the exact same quantity of exactly the same ingredients. The 'regular' presentation condition consisted of a mix of the ingredients, which were simply placed in the middle of the plate. In the 'neat' presentation condition, the ingredients together with the sauces were placed side by side without touching each another. Lastly, for the 'art-inspired' condition, the ingredients were placed on the plate in a very specific manner, inspired by one of Wassily Kandinsky's abstract paintings [26]. The painting that served as the inspiration for this dish was 'Painting number 201' (see Figure 1), and was arbitrarily chosen by the authors ${ }^{\mathrm{b}}$. It was described as 'nonobjective painting' by the artist himself, a landscape of colour free of descriptive devices [27]. Kandinsky's theories on colour and harmony could supposedly be applicable to any matter, or medium [28].

Before being placed on the plate, the vegetables and condiments were prepared in exactly the same manner for all three presentations. While the sauces were specifically laid out on the plate for the neat and art-inspired presentations, they were mixed with all the elements of the salad for the regular presentation. The plate on which the food was served consisted of a white rectangle of cardboard (dimensions of $270 \times 180 \mathrm{~mm}$ ).

The food consisted of a relatively complex salad with 17 distinct components made up of a total of 30 ingredients. They included three types of elements: vegetables, sauces (purees and a reduction), and condiments. The 17 components of the dish were as follows:

- Vegetables: seared Portobello slice, shimeji mushrooms (briefly boiled with a sweet vinegar marinade), cooked and raw broccoli sprouts, a variety of endive salad, raw red and yellow pepper cut into fine brunoises, one slice of raw red pepper, three slices of red pepper skin fine julienne, half a slice of raw yellow pepper, raw cauliflower sprouts, five slices of mange-tout fine julienne, and half a mange-tout.

- Sauces: beet purée, carrot purée, cauliflower and lemongrass crème, mushroom essence with squid ink, and, finally, pepperoncino oil.

- Condiments: Spanish olive oil, and Maldon sea salt.

A more detailed description of how to prepare each of the elements can be found in the culinary worksheet presented in Additional file 1. 


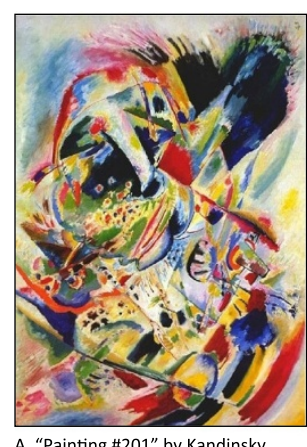

A. “Painting \#201” by Kandinsky.

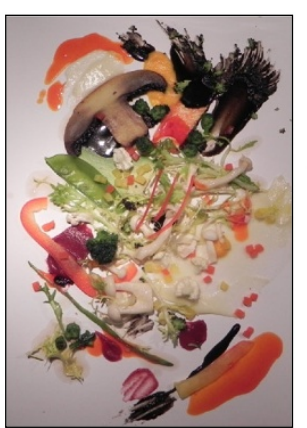

B. Kandinsky-inspired artistic presentation of food.

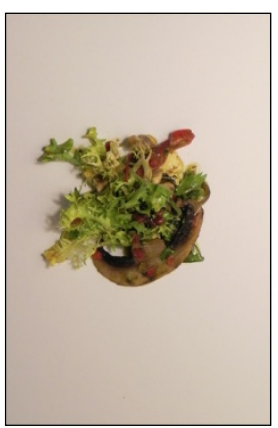

C. Regular presentation

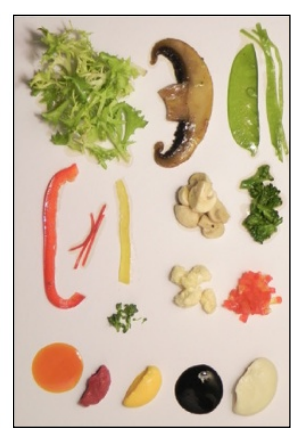

D. Neat presentation

Figure 1 The Kandinsky painting used as the inspiration for the dish (A), and the three different visual arrangements presented (B, C, D). Note that the three arrangements consisted of the same quantity of the same ingredients.

\section{Procedure}

A between-participants experimental design was used. The experimental setting, which was the same for all participants, was designed to replicate a typical restaurant table (see Figure 2) in a dark room, isolated by means of a curtain. On the table and over a white tablecloth were placed a fork, a knife, a paper napkin and a glass of water. The only lighting in the room, a small lamp, was directed at the dish.

The three conditions were randomized across the various testing times (between 10:00 and 17:00 hrs) and gender was balanced for each condition. The experiment lasted for approximately twenty minutes. Upon completing the consent form, the participants were seated at the table and told the procedure by the experimenter. The participants were also instructed that they would be presented with a plate of food, a salad, and asked to eat it. Before they could start eating, they were asked to complete a questionnaire con- cerning the visual aspects of the salad. Moreover, the participants were informed that after completion of the first questionnaire, they would be allowed to eat as much of the salad as they liked and that after they had finished they would be given another questionnaire to complete. While the experimenter explained this procedure, the dish was plated in an adjacent room. None of the participants were aware of the existence of different visual presentations and no further information was given concerning the aims of the study or the food they were about to eat and its preparation. When the dish was ready, it was placed on the table in front of the participant as shown on Figure 1, together with the first questionnaire. The participants were left alone while eating the food and completing the questionnaires.

All of the questions were presented using 10-point Likert scales. The first questionnaire was designed to assess the visual appeal of the dish and the participant's

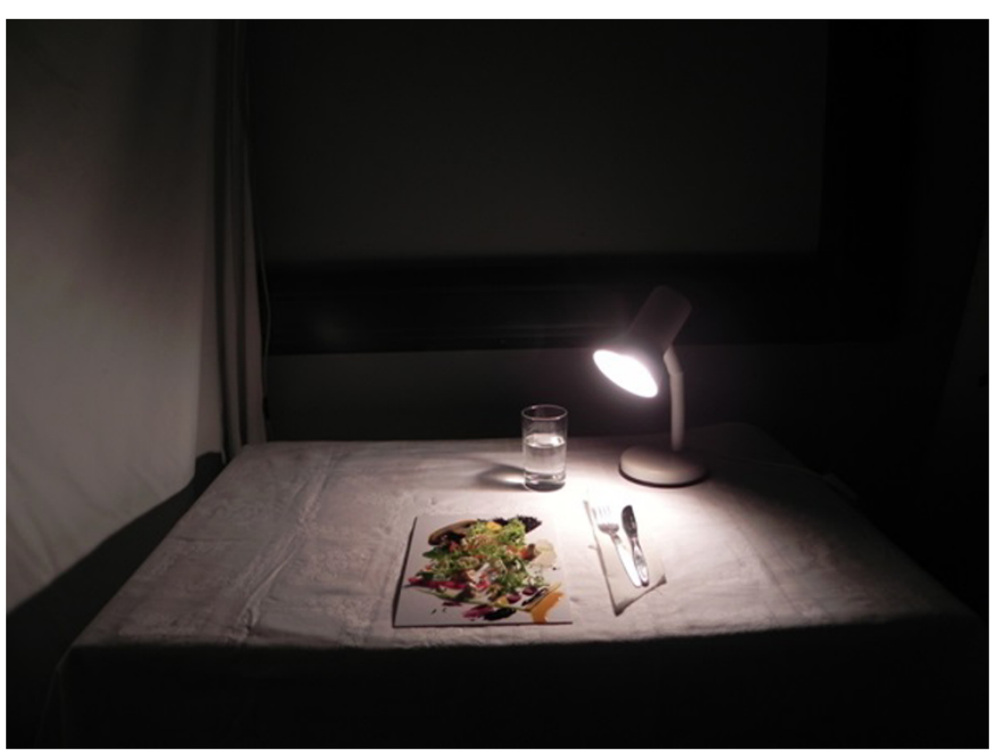

Figure 2 Setting in which the experiment was conducted. 
expectations. The second questionnaire assessed the perception of intensity of different taste attributes (saltiness, bitterness, sourness, and sweetness) and again the same questions as asked in the first questionnaire (liking, tastiness and willingness to pay), this time testing the actual experience of the food rather than merely the participants' expectations about it. For a complete list of the questions before and after consumption, see Table 1.

While similar questions were asked before and after consumption, we assumed that the preliminary judgments were based solely on the visual attributes of the food, while the latter judgments would provide information about the eating experience and the impression the food left in the mind of the participant.

\section{Results}

The effect of the three visual arrangements on participants' responses to each of the questions in the two questionnaires (pre- and post-consumption) was analyzed using a mixed model (to fit the data), including participants as a random factor (in order to account for any betweenparticipants variability). Furthermore, we included the following as fixed factors in the model: gender, age, whether the participant considered his/herself to be a 'foodie' or not, how much they enjoyed eating vegetables, and how interested they were in the visual arts, in order to control for the effect of such variables on the results of each question.

Three of the variables tested (willingness to pay for the dish, liking, and tastiness) were assessed before and after consumption. The participants' ratings concerning these three variables were analyzed by pooling together the data, including consumption of the food (that is: whether the data belonged to the questionnaire presented before or after consumption) as a further factor in the model. Note that the effect of food consumption could vary depending on the dish presented. The significant factors resulting from the analysis performed on the three variables are shown in Table 2.

Post-hoc t-tests (Bonferroni corrected, alpha $=.05 / 3, \mathrm{df}=$ 19) were used in order to assess the difference between the ratings given by the participants for each presentation. In particular, statistically significant effects between the type of presentation were found for five of the items examined (see Figure 3): The art-inspired dish was considered as being presented in a more 'complex' and 'artistic' manner, and was liked more than either of the other two presentations. The expected tastiness of the food was also affected by the presentation, with the art-inspired dish associated with significantly higher ratings as compared to both the neat and the regular presentations. The participants were also keen to pay twice as much for the artistically presented dish than for the dishes in the other presentations. It is worth mentioning that the ratings concerning the regular and the neat presentations did not reveal any significant differences for any of the questions.

Only one variable was significantly affected by the consumption of the dish. The results revealed an increase of $18 \%$ in the tastiness ratings for the art-inspired presentation (6.8 \pm 1.8 before consumption, $8.3 \pm 1.5$ after consumption, this difference was statistically significant: $\mathrm{t}=$ $2.7, P<.01$ ), while the ratings decreased slightly in the regular presentation $(6.0 \pm 1.8$ before consumption, $5.6 \pm$ 2.2 after consumption). The latter difference was, however, not statistically significant $(\mathrm{t}=-.5, P=.5)$ as shown by the interaction plot (see Figure 4; coefficient value of the interaction: $-.74, \mathrm{P}<.05)$. For the neat presentation, the consumption did not have any effect on the tastiness ratings.

Eating the food led to an increase in ratings of the tastiness of the food in the case of the art-inspired dish, likely showing that the aesthetic value of this visual arrangement

Table 1 Questionnaires used in this study

\begin{tabular}{|c|c|}
\hline $\begin{array}{l}\text { Questionnaire 1. It was presented simultaneously with the dish, and } \\
\text { aimed to measure the visual appeal of the food and the participant's } \\
\text { expectations }\end{array}$ & $\begin{array}{l}\text { Questionnaire 2. It was presented after the participant had finished } \\
\text { eating, aiming to measure different cues of the experience the } \\
\text { participant had eating the dish and other general impressions }\end{array}$ \\
\hline How complex does this dish appear to be? & How salty was the food? \\
\hline How much do you like the presentation of the food? & How bitter was the food? \\
\hline How much would you be willing to pay for this dish (in British Pounds)? & How sour was the food? \\
\hline Please rate how artistically arranged you think this plate is? & How sweet was the food? \\
\hline How tasty does this dish look? & How much did you like this dish? \\
\hline \multirow[t]{7}{*}{ How healthy do you think this dish is? } & How much would you be willing to pay for the dish (in British pounds)? \\
\hline & How tasty did you find the dish? \\
\hline & How full are you after eating this plate? \\
\hline & Do you generally enjoy eating vegetables? \\
\hline & How many ingredients do you think the dish contained? \\
\hline & Do you consider yourself to be a 'foodie'? \\
\hline & How interested are you in the visual arts? \\
\hline
\end{tabular}


Table 2 The left part of the table shows the significant factors in the mixed models highlighting the significant effects of the fixed variables, the right part shows the post-hoc test (Bonferroni corrected) significance values, the relevant means and the standard deviations, values in bold indicate significant results in the comparisons

\begin{tabular}{|c|c|c|c|c|c|c|c|c|}
\hline Question & $\begin{array}{l}\text { Significant } \\
\text { factors }\end{array}$ & $\begin{array}{l}\text { Coefficient } \\
\text { value }\end{array}$ & $\mathrm{t}$-value & $P$ values & $\begin{array}{l}\text { Means } \pm \text { standard deviations } \\
\text { for each presentation }\end{array}$ & $\begin{array}{l}\text { Art versus } \\
\text { Regular }\end{array}$ & $\begin{array}{l}\text { Art versus } \\
\text { Neat }\end{array}$ & $\begin{array}{l}\text { Neat versus } \\
\text { Regular }\end{array}$ \\
\hline \multirow[t]{3}{*}{ Complexity } & \multirow[t]{3}{*}{ Presentation } & \multirow[t]{3}{*}{-.97} & \multirow[t]{3}{*}{-2.83} & \multirow[t]{3}{*}{.0064} & Art-inspired $(7.5 \pm 1.95)$ & $t=2.28$ & $t=2.51$ & $t=.65$ \\
\hline & & & & & Regular $(5.7 \pm 1.7)$ & $\boldsymbol{P}$ value $<.05$ & $\boldsymbol{P}$ value $<.01$ & $\boldsymbol{P}$ value $=.51$ \\
\hline & & & & & Neat $(5.2 \pm 2.5)$ & & & \\
\hline \multirow{3}{*}{$\begin{array}{l}\text { Artistic } \\
\text { presentation }\end{array}$} & \multirow[t]{3}{*}{ Presentation } & \multirow[t]{3}{*}{-.99} & \multirow[t]{3}{*}{-2.61} & \multirow[t]{3}{*}{.01} & Art-inspired $(7.9 \pm 2.3)$ & $t=3.04$ & $t=2.4$ & $t=-.71$ \\
\hline & & & & & Regular $(5.7 \pm 2.2)$ & $\boldsymbol{P}$ value $<.01$ & $\boldsymbol{P}$ value $<.05$ & $\boldsymbol{P}$ value $=.47$ \\
\hline & & & & & Neat $(6.2 \pm 2.12)$ & & & \\
\hline \multirow[t]{3}{*}{ Liking } & \multirow[t]{3}{*}{ Presentation } & \multirow[t]{3}{*}{-1.18} & \multirow[t]{3}{*}{-3.36} & \multirow[t]{3}{*}{.0014} & Art-inspired (8.0 \pm 1.8$)$ & $t=5.5$ & $t=5.3$ & $t=.01$ \\
\hline & & & & & Regular $(5.6 \pm 2.0)$ & $\boldsymbol{P}$ value $<.001$ & $\boldsymbol{P}$ value $<.01$ & $\boldsymbol{P}$ value $=.90$ \\
\hline & & & & & Neat $(5.5 \pm 2.3)$ & & & \\
\hline \multirow{3}{*}{$\begin{array}{l}\text { Willingness } \\
\text { to pay }\end{array}$} & \multirow[t]{3}{*}{ Presentation } & \multirow[t]{3}{*}{-116.9} & \multirow[t]{3}{*}{-2.30} & \multirow[t]{3}{*}{.02} & Art-inspired $(425 \pm 511)$ & $t=3$ & $t=3.2$ & $t=0.3$ \\
\hline & & & & & Regular $(208 \pm 283)$ & $\boldsymbol{P}$ value $<.01$ & $\boldsymbol{P}$ value $<.01$ & $\boldsymbol{P}$ value $=.74$ \\
\hline & & & & & Neat $(214 \pm 268)$ & & & \\
\hline \multirow[t]{5}{*}{ Tastiness } & \multirow[t]{3}{*}{ Presentation } & \multirow[t]{3}{*}{-.70} & \multirow[t]{3}{*}{-2.12} & \multirow[t]{3}{*}{.03} & Art-inspired $(7.5 \pm 1.8)$ & $t=3.9$ & $t=4.5$ & $t=.73$ \\
\hline & & & & & Regular $(5.8 \pm 2)$ & $\boldsymbol{P}$ value $<.01$ & $\boldsymbol{P}$ value $<.01$ & $\boldsymbol{P}$ value $=.46$ \\
\hline & & & & & Neat $(5.4 \pm 2.2)$ & & & \\
\hline & Consumption & 1.8 & 2.40 & .01 & & & & \\
\hline & $\begin{array}{l}\text { Consumption: } \\
\text { presentation }\end{array}$ & -.74 & -2.07 & .04 & & & & \\
\hline
\end{tabular}

made the food more enjoyable to eat. The food might also have been tastier than expected; even though the different perceived tastes (in terms of the rated saltiness, sweetness, bitterness, and sourness of the food) did not differ significantly between the three conditions.

The participants' appetite level was assessed before displaying the food, using a 10-point Likert scale. No significant differences were found between the three groups ('Art-inspired' group: $\mathrm{M}=5.05, \mathrm{SD}=2.03$; 'Regular' group: $\mathrm{M}=5.05, \mathrm{SD}=1.90$; 'Neat' group: $\mathrm{M}=5.85, \mathrm{SD}=1.87$ ). $\mathrm{A}$ Kolmogorov-Smirnov test revealed that the data from the three groups was normally distributed $(P=.2$ for the 'Art-inspired' group, $P=.058$ for the 'Regular' group, and $P=.082$ for the 'Neat' group).

\section{Discussion}

We compared an art-inspired food presentation to a condition where the same ingredients were arranged in a more regular manner, or else in a neat (and hence effortful) but non-artistic manner. Before the participants had tasted the food, the artistic plating was liked more than both the regular and neat food presentations, as well as being recognized as more artistic and complex than either of the other two presentations, even though the participants were not informed that the dish was supposed to mimic a work of art.
After eating, participants rated the food presented in the art-inspired as being more flavourful.

\section{Art-infused food design}

The fact that the participants in the present study liked the art-inspired dish more presumably reflects that they were actually able to recognize an artistic pattern in the food intuitively. The debate concerning what can be considered as 'art' has, for a long time, involved philosophers, aesthetes, psychologists, and, more recently, cognitive neuroscientists $[29,30]$. It is reasonable to assume that since art involves, at least in part, the ability to communicate feelings and sensations [30,31], the art-inspired presentation of the food could have been an edible rendition of the message originally intended by Kandinsky on the canvas 'Painting number 201'. Indeed, the differences between ratings of 'liking', 'artistic value' and 'complexity' could be attributed to an absolute aesthetic value that would have been transferred from the painting to the food design. According to another point of view, however, one could simply argue that art is that which viewers categorize as such $[32,33]$.

The concept of an identifiable pattern is not an unusual idea in the field of art [34], and this could have led the participants to define the dish as being more artistic because patterns (of colour and shape) were easy to 

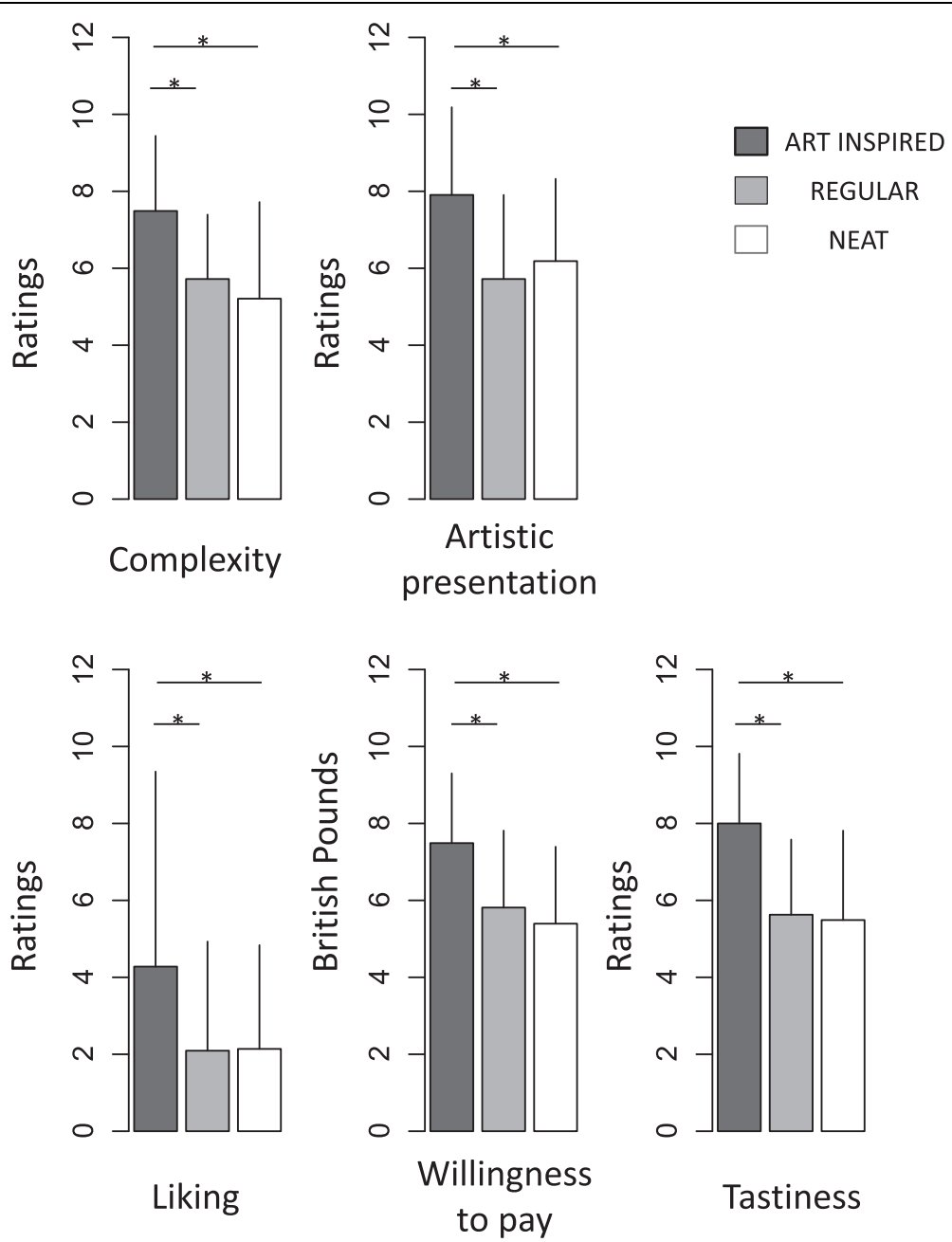

Figure 3 Bar graphs show the mean values and the standard deviations of the ratings for each of the variables that showed a statistically significant effect of the presentation (complexity, liking, artistically arrangement, tastiness, and willingness to pay). Statistically significant differences are highlighted ( $\left.{ }^{*} \mathrm{P}<.05\right)$ between the art-inspired presentation, the regular plating, and the neat presentation of the food.

identify. If this were to have been the case, the identified patterns could also have influenced the participants' liking judgments. Although participants' personal preferences (or taste) in art could have influenced our results, it should be noted that the display of art has been shown to activate reward systems in the human brain [35]. Results reported by Ramachandran [36] show that people may experience some sort of reward when processing visually complex stimuli (as, indeed, the art-inspired presentation was perceived by our participants). Furthermore, in one experiment, both art experts and novices were found to rate more complex artistic stimuli as being more interesting [31]. Indeed, the way the diners' interest is cultivated in high-end restaurants through highly complex food preparations and presentations, amongst other factors, is probably a key aspect of designing pleasurable food experiences.
A different perspective on the effect of plating on participants' responses to the food would be to consider the 'Art-Infusion' phenomenon as advanced by Hagtvedt and Patrick [37]. According to this theory, consumers evaluate products more favourably when they are associated with art. In this case, the art-inspired dish might have implicitly suggested a connotation of higher value (or effort) through the visual display, value that might have helped to deliver a more pleasurable eating experience.

Our participants were willing to pay more for the artistic presentation of the dish, both before and after tasting it (note that the consumption of the food did not modify people's price estimation). These results are consistent with previous research suggesting that the aesthetic presentation of food can result in people being willing to pay more for it [25]. It is important to assess any potential explanation as to why people may 


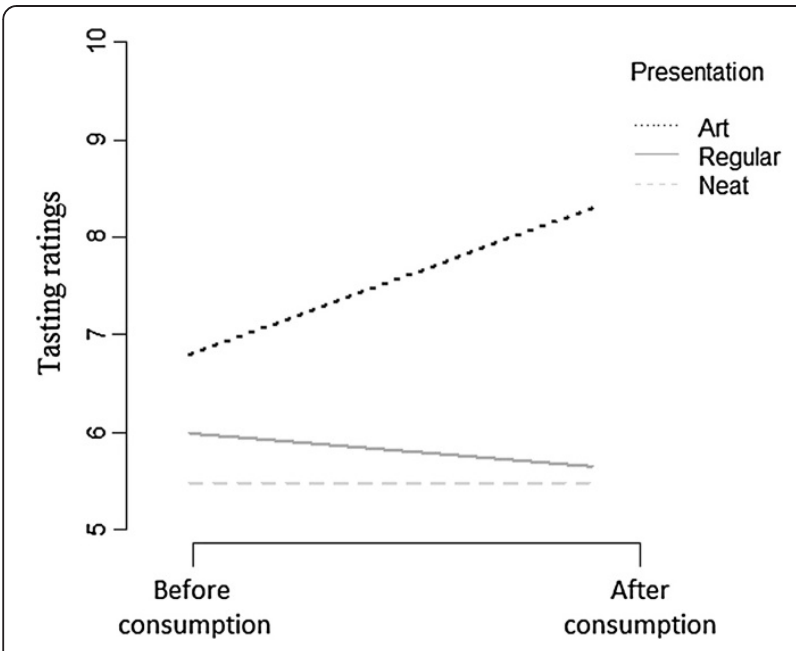

Figure 4 Interaction plot showing the effect of the consumption of the dish on the tastiness ratings for the three presentations.

pay more for an art-inspired dish (for example, a plate of salad inspired by Kandinsky); for instance, we might consider how the 'effort' involved in preparing a dish can be appreciated by a diner and, thus, change the perceived value of the dish. Neatness and complexity might be some of the elements that people are ready to pay more for as well; as the philosopher Denis Dutton puts it, the value of an artwork is rooted in the assumptions about the human performance underlying its creation [38].

\section{A taste of Kandinsky}

When the participants in the present study were asked to rate the expected tastiness of the dishes before they had sampled the food, no difference was reported between the three conditions. Even if the visual properties of the artinspired condition received higher ratings than the other two conditions, participants were not expecting it to taste better. Interestingly, after consumption, the art-inspired presentation was rated as significantly tastier (up to $18 \%$ more) than the other two, even though they were composed of the same quantity of the same ingredients (see Figure 4). A higher rating for the experienced tastiness ${ }^{\mathrm{c}}[39,40]$ of the Kandinsky-inspired dish clearly shows that plating can have an important effect on flavour perception. This observation is consistent with previous findings [22], confirming that what we see can indeed influence what we taste. In addition to the arguments discussed in the previous sections, we would argue that such percept could be the result of more enjoyment elicited by the act of consuming an aesthetically pleasing product, whose creation requires a more skilful and effortful act. This result supports the theory that cultivating uniqueness in plating and presentation could be central to delivering pleasurable food experiences.

\section{Art or novelty?}

The higher ratings given to the art-inspired presentation of food could also be an effect of novelty; one might wonder if any salad that is not just mixed and placed on a plate would seem to be more 'artistic'. However, the elements of a salad placed in any form would not necessarily seem more 'artistic', given the risk that the plating might end up being considered as messy, and therefore less appealing. Indeed, Zellner and her colleagues have shown that people are more willing to try and tend to like a neat presentation more rather than a messy one [25].

Different food designs could be used in future research on plating, to understand how artistry and novelty are processed and evaluated by diners, and how this can impact on the eating experience. For instance, a novel and artistic plating could be compared to a novel but nonartistic one.

\section{Limitations of present research and directions for future research}

There are a number of limitations with the present study that should be borne in mind: First, it is important to note that mixed culinary elements on a plate (for example, two different sauces, or one sauce and one garnish) may have merged to create a new flavour. In this sense, the way in which the three dishes are arranged may, in fact, have led to their having different flavours (physically - as opposed to any effect that they have due to the psychological impact of the dish). The participants were not asked to eat all of the food, but rather to eat as much as they wanted. Interestingly, those participants in the art-inspired and regular presentations tended to eat all of the food, while they left more when presented the neat presentation; some of the participants would try the various elements in the dish without necessarily eating them all. It would be interesting to know the extent to which seeing the various components visually 'integrated', rather than separated, affected consumption behaviour and probably how flavourful the food ended up being perceived.

It is also important to note that the present study was conducted in a laboratory setting, a most unusual place in which to eat, granted, and with most of the participants being students [41]. This might explain the large standard deviation found for how much participants were ready to pay for the dish (with a few of the participants being willing to pay much more than the average for the dish). Although the experimental set-up attempted to replicate a restaurant table, the contextual variables of the laboratory setting may, for instance, have influenced how much the participants were willing to pay (presumably being lower than would have been expected had the same dish been served in a restaurant context) ${ }^{\mathrm{d}}$. Moreover, another possible bias in the results regards the time of day at which the participants consumed the food. Indeed, it would be 
likely that higher ratings would have been obtained from hungry participants and lower ratings for participants performing the experiment in the early afternoon (for example, right after lunch). However, since conditions were randomly distributed across the time of the day, it is reasonable to assume that the groups had an equal number of 'hungry' and 'full' participants. As a consequence, this might have affected the variance of the data within groups, leaving untouched the differences between groups.

The fact that our participants received monetary compensation for taking part in this study might also have influenced their experience, as it is unusual experience for most of us to be paid to eat. It would also be intriguing to see whether preparing/presenting the dish in different contexts (for example, science lab/gastronomy event/restaurant) would change the way in which people respond to it as well ${ }^{\mathrm{e}}$.

Future research may, in turn, take into account the differences that arise in the perceived attributes of an art-inspired food when exactly the same dish is served in one context versus another $[9,42,43]$. One question that still needs to be addressed is whether it is possible to spot different visual patterns in the dish, and if so, which ones in particular may lead people to consider a dish as being artistic or not. It would also be interesting to test how more specific cues borrowed from the visual arts interact (here we are thinking of balance, symmetry, or colour associations). Future studies may also attempt to understand how knowing (before tasting) the story about the dish and its inspiration can impact the perception of the food. In addition, there is a need to develop objective measures of the resulting complexity of food presentations, since the various aspects of a visual arrangement can affect the resulting complexity of an image, in terms of its various components and their interaction.

\section{Conclusions}

The results of the study reported here provide evidence for the idea that there are differences in the expectations and consumption experience of a dish as a result of the various elements having been artistically arranged on the plate. Diners intuitively attribute an artistic value to the food, find it more complex and like it more when the culinary elements are arranged to look like an abstract-art painting. More importantly, people are ready to pay more for the food when it is presented in an aesthetically pleasing manner, both before and after trying it. Interestingly, consuming the artistically arranged dish enhanced people's assessment of the palatability of the food.

Taking these results into account, it could be assumed that the diner's hedonic and sensory perception of a dish is influenced by the expectations that have been established by visual cues. Complexity and neatness could be key aspects to produce an aesthetic display of ingredients. Furthermore, the positive values set by visual cues seem to be transferred to the perceived flavour of foods.
Here, we argue that using artistic inspiration in the design of the culinary experience, even when used implicitly, can indeed enhance the enjoyment of food.

The visual appeal of food has been, and will always be, an important matter to entice the appetite, ultimately enhancing the flavours of culinary creations. While chefs rely mostly on their intuition and expertise to plate their dishes [7], we suggest that studying food presentations under the lens of psychology and sensory science could give precious insights to the so far empirical, art of plating.

'Color is forever a part of our food, a visual element to which human eyes, minds, emotions and palates are sensitive. Perhaps through eons of time, man has come to build up strong and intuitive associations between what he sees and what he eats. A good meal, to say the least, is always a beautiful sight to behold.'

(Birren, 1963 [44]).

\section{Endnotes}

${ }^{a}$ Chefs in high-end restaurants tend to put a lot of thought in the design of the visual appearance of their dishes to enhance the experience of flavour [7], making this an opportunity for scientist to observe the contextual effects of plating on flavour perception.

${ }^{b}$ We wanted to prove the effect of an aesthetic food display on flavour perception. We thought that rather than designing a food display that would look 'nice' to us, we would choose a visual display widely established as being aesthetic, as the work of Kandinsky is recognised to be, and transform it into a dish of food.

'We assume that the term 'tastiness' could be interpreted in the sense of 'flavourful' or 'delicious'.

din fact, we used the same questionnaire to assess the perception of the art-inspired dish in the 'Food and Wine Matching: A South American Perspective' event held at the University of London, UK, 7 February 2013, as part of the London Enology Series. The results of this event were consistent with those obtained in the main experiment reported here. Compared to the main study, statistically significant differences $(P<.05)$ were found regarding people's willingness to pay for the dish $(£ 3.53 \pm 3.1$ in the main experiment, $£ 7.60 \pm 3.3$ in the event in London), as well as the estimated number of ingredients needed to create the dish $(11.75 \pm 5.9$ in the main experiment versus $16.89 \pm 5.9$ in the event in London). Such differences may be attributable to the different public that tasted the food (mostly students in the laboratory, people interested in wine and food in this event), but also to the different experimental settings in which the two studies were conducted. Indeed, in the London event, the participants were aware of the facts concerning the preparation of the dish, such as the painting that had inspired it and the cook preparing the food. This knowledge could have biased their judgment 
on the actual difficulty of preparing the dish, resulting in their giving a higher estimate of the price and number of ingredients in comparison with the main experimental setting. (Of course, it could also be that food simply costs more in London than in Oxford where the main study was conducted.) This evidence suggests the importance of the context in which people eat, as well as the importance of the information regarding the food that they are eating, in their evaluation of a dish.

${ }^{\mathrm{e}}$ In the original culinary version of this art-inspired dish, the chef offers truffle-oil scented paintbrushes to eat the salad. While people are comfortable eating with the use of a paintbrush in a large social setting, preliminary experiments have revealed that many of our participants were somewhat reluctant to use such a 'modernist' cutlery when we tested them individually in the laboratory.

\section{Additional file}

\section{Additional file 1: Culinary worksheet for the 'Taste of Kandinsky' dish.}

\section{Competing interests}

The authors confirm that there are no conflicts of interest.

\section{Authors' contributions}

CM created the design of the 'Salad with a taste of Kandinsky' dish used in this study. CV, EG, and CM worked on the experimental design of the study, under the supervision of CS. CM, CV, and EG conducted the experiment at the Crossmodal Research Laboratory, Oxford University. CM effectuated all the culinary preparations. EG and CV analysed the data. CM, CV, EG, and CS were all involved in the writing of the manuscript. All authors read and approved the final version of the manuscript.

\section{Authors' information}

CV DPhil candidate at the department of Experimental Psychology, University of Oxford.

$\mathrm{CM}$ is a classically trained professional cook and researcher. He is the first Chef in Residence at the Crossmodal Research Laboratory.

EG is a researcher working at Politecnico di Milano, interested in understanding sensory experience.

CS is a Professor of Experimental Psychology, and Head of the Crossmodal Research Laboratory at the Department of Experimental Psychology, University of Oxford.

\section{Acknowledgements}

CS is funded by the AHRC grant 'Rethinking the Senses' within the Science in Culture theme. CM would like to thank 'Comes Cake' for the picture used as cover image. The authors confirm that they received no external funding for this research.

\section{Received: 30 January 2014 Accepted: 2 May 2014}

Published: 20 June 2014

\section{References}

1. Barba EB: My cuisine is tradition in evolution. [http://www.swide.com/ food-travel/chef-interview/michelin-starred-chef-an-interview-with-massimobottura/2013/4/23]

2. Spence C: Multisensory flavour perception. Curr Biol 2013, 23:365-369.

3. Stevenson RJ: The Psychology Of Flavour. Oxford: Oxford University Press; 2009.

4. Verhagen JV, Engelen L: The neurocognitive bases of human multimodal food perception: Sensory integration. Neurosci Biobehav Rev 2006, 30:613-650.

5. Köster EP: Diversity in the determinants of food choice: A psychological perspective. Food Qual Prefer 2009, 20:70-82.
6. Meiselman HL: Dimensions of the meal: The science, culture, business, and art of eating. Gaithersburg, MA: Aspen Publishers; 2000

7. Spence C, Piqueras-Fiszman B: The Perfect Meal: The Multisensory Science of Food and Dining. Oxford: Wiley-Blackwell; in press.

8. Herman CP, Roth DA, Polivy J: Effects of the presence of others on food intake: A normative interpretation. Psychol Bull 2003, 129:873-886.

9. Bell R, Meiselman HL, Pierson BJ, Reeve WG: Effects of adding an Italian theme to a restaurant on perceived ethnicity, acceptability, and selection of foods. Appetite 1994, 22:11-24.

10. Wansink B, Van Ittersum K: Fast food restaurant lighting and music can reduce calorie intake and increase satisfaction. Psychol Rep 2012, 111:1-5.

11. Harrar V, Spence C: The taste of cutlery. Flavour 2013, 2:21.

12. Spence $C$, Harrar $V$, Piqueras-Fiszman B: Assessing the impact of the tableware and other contextual variables on multisensory flavour perception. Flavour 2012, 1:1-12.

13. Piqueras-Fiszman B, Alcaide J, Roura E, Spence C: Is it the plate or is it the food? Assessing the influence of the color (black or white) and shape of the plate on the perception of the food placed on it. Food Qual Prefer 2012, 24:205-208.

14. Piqueras-Fiszman B, Spence C: The influence of the color of the cup on consumers' perception of a hot beverage. J Sens Stud 2012, 27:324-331.

15. Stewart $P$, Goss E: Plate shape and colour interact to influence taste and quality judgments. Flavour 2013, 2:27

16. Delwiche J: The impact of perceptual interactions on perceived flavour. Food Qual Prefer 2004, 15:137-146.

17. Spence C, Levitan CA, Shankar MU, Zampini M: Does colour influence taste perception in humans? Chemosens Percept 2010, 3:68-84.

18. Okajima K, Spence C: Effects of visual texture on taste perception. i-Perception 2011, 2:966.

19. Imram N: The role of visual cues in consumer perception and acceptance of a food product. Nutr Food Sci 1999, 99:224-230.

20. Watz B: The entirety of the meal: A designer's perspective. J Foodservice 2008, 19:96-104.

21. Yeomans MR, Chambers L, Blumenthal H, Blake A: The role of expectancy in sensory and hedonic evaluation: The case of smoked salmon ice-cream. Food Qual Prefer 2008, 19:565-573.

22. Delwiche JF: You eat with your eyes first. Physiol Behav 2012, 107:502-504.

23. Apicius: Cooking and Dining in Imperial Rome. (c. $1^{\text {st }}$ Century). Translated by Vehling JD. Chicago: University of Chicago Press; 1936.

24. Zellner DA, Lankford M, Ambrose L, Locher P: Art on the plate: Effect of balance and color on attractiveness of, willingness to try and liking for food. Food Qual Prefer 2010, 21:575-578.

25. Zellner DA, Siemers E, Teran V, Conroy R, Lankford M, Agrafiotis A, Ambrose $L$, Locher P: Neatness counts. How plating affects liking for the taste of food. Appetite 2011, 57:642-648.

26. Schapiro M: The nature of abstract art. In Modern art, 19th and 20th Centuries: Selected papers. New York: George Braziller; 1937:77-98.

27. Gallery label text, MoMA museum. [http://www.moma.org/collection/ browse_results.php?object_id=79452]

28. Kandinsky W: Concerning the Spiritual in Art, Especially in Painting (1914). Translated by Sadler MTH. New York: Dover Publications; 1977.

29. Carey J: What Good Are the Arts? London: Faber \& Faber; 2005.

30. Zeki S: Inner Vision: An Exploration of Art and the Brain. Oxford: Oxford University Press; 2000.

31. Silvia PJ: Emotional responses to art: From collation and arousal to cognition and emotion. Rev Gen Psychol 2005, 9:342-357.

32. Bourdieu P, Darbel A: The Love of Art: European Art Museums and Their Public. Oxford: Blackwell; 1997.

33. Dewey J: Having an experience. In The Later Works, 1925-1953: Art as Experience. Edited by Boydston JA, Dewey J. Carbondale: Southern Illinois University Press; 1989:42-63.

34. Behrens RR: Art, design and Gestalt theory. Leonardo 1998, 31:299-303.

35. Lacey S, Hagtvedt H, Patrick VM, Anderson A, Stilla R, Deshpande G, Hu X, Sato JR, Reddy S, Sathian K: Art for reward's sake: Visual art recruits the ventral striatum. Neurolmage 2011, 55:420-433.

36. Ramachandran VS: The Emerging Mind. London: Profile Books; 2003.

37. Hagtvedt H, Patrick VM: Art infusion: The influence of visual art on the perception and evaluation of consumer products. J Mark Res 2008, 45:379-389.

38. Dutton D: The Art Instinct, Beauty, Pleasure, and Human Evolution. New York: Bloomsbury Press; 2009. 
39. Spence C, Smith B, Auvray M: Confusing tastes and flavours. In The Senses. Edited by Matthen M, Stokes D. Oxford: Oxford University Press; in press.

40. Rozin P: "Taste-smell confusions" and the duality of the olfactory sense. Percept Psychophys 1982, 31:397-401.

41. Henrich J, Heine SJ, Norenzayan A: The weirdest people in the world? Behav Brain Sci 2010, 33:61-135.

42. Green DM, Butts JS: Factors affecting acceptability of meals served in the air. J Am Diet Assoc 1945, 21:415-419.

43. Meiselman HL, Johnson JL, Reeve W, Crouch JE: Demonstrations of the influence of the eating environment on food acceptance. Appetite 2000, 35:231-237.

44. Birren F: Color and human appetite. Food Technol 1963, 17:45-47.

doi:10.1186/2044-7248-3-7

Cite this article as: Michel et al: A taste of Kandinsky: assessing the influence of the artistic visual presentation of food on the dining experience. Flavour 2014 3:7.

\section{Submit your next manuscript to BioMed Central and take full advantage of:}

- Convenient online submission

- Thorough peer review

- No space constraints or color figure charges

- Immediate publication on acceptance

- Inclusion in PubMed, CAS, Scopus and Google Scholar

- Research which is freely available for redistribution 